\title{
Asperitas - a newly identified cloud supplementary feature
}

Article

Accepted Version

Harrison, R. G., Pretor-Pinney, G., Marlton, G. J., Anderson, D. G., Kirshbaum, D. J. and Hogan, R. J. (2017) Asperitas - a newly identified cloud supplementary feature. Weather, 72 (5). pp. 132-141. ISSN 0043-1656 doi:

https://doi.org/10.1002/wea.2996 Available at https://centaur.reading.ac.uk/69830/

It is advisable to refer to the publisher's version if you intend to cite from the work. See Guidance on citing.

To link to this article DOI: http://dx.doi.org/10.1002/wea.2996

Publisher: Royal Meteorological Society

All outputs in CentAUR are protected by Intellectual Property Rights law, including copyright law. Copyright and IPR is retained by the creators or other copyright holders. Terms and conditions for use of this material are defined in the End User Agreement.

\section{www.reading.ac.uk/centaur}

\section{CentAUR}

Central Archive at the University of Reading 
Reading's research outputs online 


\title{
Asperitas - a newly identified cloud supplementary feature
}

R. Giles Harrison +, Gavin Pretor-Pinney*+, Graeme J. Marlton ${ }^{+}$, Graeme D. Anderson`, Daniel J. Kirshbaum; Robin J. Hogan ${ }^{\Delta+}$

${ }^{+}$Department of Meteorology, University of Reading

*The Cloud Appreciation Society

- Met Office, Fitzroy Road, Exeter

- Department of Atmospheric and Oceanic Sciences, McGill University, Montréal Canada

${ }^{\triangle}$ ECMWF, Shinfield Park, Reading

Keywords: cloud classification; wave cloud; citizen science;

Running head: Aperitas

\begin{abstract}
Cloud images obtained through a crowd-sourced international observing network suggest a cloud variety that has hitherto not been explicitly classified. This cloud feature shows a roughened base, which, under some solar illumination conditions, provides a particularly dramatic appearance. The growing body of photographic observations have led the World Meteorological Organisation to consider adding 'asperitas' to the 2017 edition of the International Cloud Atlas as a new form of supplementary cloud feature. We compare reported sightings with available meteorological data to investigate the conditions that give rise to this newly recognised cloud description.
\end{abstract}

\section{Introduction}

Since the early 19th century, clouds have been identified using the Linnean system first proposed by Luke Howard, which was subsequently adopted as the official international classification scheme of the World Meteorological Organisation (WMO). A comprehensive table of all available terms and combinations is given in Volume 1 of the WMO Cloud Atlas, (e.g. WMO, 1975). This publication provides an extensive set of detailed descriptions beyond the distinction between layer and convective clouds at different vertical levels. It is the internationally agreed standard reference manual on the classification and observation of clouds and other meteorological phenomena. The Cloud Atlas also effectively presents a stable set of classifications ennobled by time and international adoption. Revisions to the 
Cloud Atlas are consequently now rare and exceptional, such as the inclusion of the intortus variety of Cirrus in $1951^{1}$.

Evidence now exists for a further cloud classification, consolidated by the widespread use of digital photography. The UK-based Cloud Appreciation Society (CAS), formed in 2005, has provided the necessary connectivity for this crowd-sourcing activity through its website and its CloudSpotter mobile app. These have enabled gathering and categorising of photographic observations from enthusiasts and the general public, which represent a form of citizen science. Citizen science has demonstrated applications to meteorology in detecting rare or widespread phenomena (e.g. Barnard et al 2016), and in this case it has demonstrated the global occurrence of a new cloud form, which had not previously been identified by the existing classification scheme (e.g. Figure 1). This particular cloud shows a characteristic feature of a chaotic and undular cloud base. It was originally informally named asperatus, but is now to be known as asperitas ${ }^{2}$.

[Figure 1]

Images collated by CAS contributors vary in composition, clarity and the extent of the associated metadata available. The increasing use of smartphones with Global Positioning System (GPS) capability means that the quality of the time and position information for the images has steadily improved, allowing reliable comparisons between images to be made. In this paper, well-authenticated sightings of asperitas are assembled and the associated meteorological circumstances investigated. This allows the atmospheric conditions to be explored and possible formation mechanisms to be considered.

\section{Sightings}

Figures 1 to 4 show exemplars of the cloud originally identified by the Cloud Appreciation Society as falling outside the conventional classification scheme, and now considered to be examples of asperitas. These have the common feature of a roughened, but not entirely wavelike cloud base, and, as these images indicate, the cloud formation is neither restricted to a narrow geographical region nor a particular time of year. Figure 1a shows a formation over Perthshire, Scotland, on 4 November 2008, with the cloud base features illuminated from below. Figure $1 \mathrm{~b}$ shows a further early example, obtained at Fort Worth, Texas on 25 March 2009, which was chosen for an analysis by Anderson (2010) because multiple images had been obtained and some ancillary meteorological data were available.

Figures 2, 3 and 4 provide more recent examples, from, respectively, northern Belgium on 9 June 2014, Dorset (UK) on 9 July 2016 and Peterborough (UK) on 27 August 2016. In these latter three cases, multiple images from the same region were submitted by users of the

\footnotetext{
${ }^{1}$ Cirrus dominated by irregularly curved filaments of ice, giving an entangled appearance.

2 from the Latin noun meaning roughness
} 
CAS CloudSpotter mobile app, providing consistency in location and the image timestamps provided. The locations and time information suggest that the cloud formation persisted for several hours in each case.

The Fort Worth, Belgium, Dorset and Peterborough sightings are discussed further in section 4, alongside the further meteorological information available. Firstly, however, some possible formation hypotheses for the cloud form are briefly discussed in section 3 .

[Figures 2,3 4]

\section{Formation hypotheses}

In general, the wave-like form apparent in the cloud images hints at an origin associated with weak oscillatory motion or structures. Oscillatory activity is readily generated in different atmospheric circumstances, such as through effects of orography (mountain wave clouds), wind shear, convection, or imbalances of the large-scale flow which generate atmospheric gravity waves. From the images alone, the partial wave features in the cloud base appear to be of order a few hundred meters to a few kilometres in wavelength, with amplitude approximately $5-10 \%$ of the wavelength.

A summary of possible routes to generate a roughened cloud base typical of asperitas was explored in the dissertation by Anderson (2010), after an analysis of the then available sightings. The mechanisms suggested were broadly associated with local turbulence, generated by instability or shear at a cloud-air interface. Anderson (2010) also remarked on the partial visual similarities between mamma and asperitas. Mamma are characterised by hanging, pouch-like protuberances at cloud base, particularly those of Cumulonimbus incus clouds (WMO, 1975). Some asperitas images are reminiscent of mamma, indicating the possibility that their cellular formation might become modified into short-range wave-like structures.

Whilst a cloud base may be statically stable, addition of wind shear can lead to oscillatory motion through Kelvin-Helmholtz instability. Such instability is frequently observed at the cloud top, but asperitas formations may be rare occurrences of Kelvin-Helmholtz instability at the cloud base, or arise from incomplete downwards propagation of the cloud top instability when the cloud layer is sufficiently thin. Instability in this case within the cloud layer would therefore lead to downward transport, giving uneven formations in the cloud base, shaped by the stable air below. Systematic examination of different formation hypotheses is needed to identify the detailed mechanism(s) behind the generation of asperitas. 


\section{Case studies}

The images described in section 2 are now discussed further, reviewing first the work undertaken by Anderson (2010) associated with the Fort Worth sighting in Figure $1 \mathrm{~b}$, and then moving on to the more recent European sightings.

[Figure 5]

\section{(a) Fort Worth}

The Fort Worth sighting of 25 March 2009 was chosen for further investigation by Anderson (2010) as multiple observations existed, due to its occurrence over a major population centre. Five photographs of this formation are archived by the CAS, taken in Fort Worth and nearby Cedar Hill, offering reliable corroborating reports. Radiosonde data are available from Fort Worth itself, from launches made around six hours before and six hours after the sightings. These soundings are shown in Figure 5(a) to (d) respectively. Figure 5e shows a composite of NOAA's NEXRAD operational S-band radar images and Figure $5 f$ shows the GOES visible satellite imagery for the region around Fort Worth at the same time. Together they show a convective system approaching from the southwest at the time the formation was observed.

The soundings show both upper level cloud (at $7 \mathrm{~km}$ ) and lower level cloud in the later sounding. Anderson (2010) performed idealized large-eddy simulations of the upper cloud layer in the Fort Worth case with CM1 (Bryan and Fritsch 2002), a nonlinear, nonhydrostatic, and compressible atmospheric model. The three-dimensional model domain used a size of $10 \mathrm{~km}$ in both horizontal directions and $11 \mathrm{~km}$ in the vertical, with a grid spacing of $100 \mathrm{~m}$ in all dimensions. Cloud microphysics processes were parameterized using the double-moment ice scheme of Morrison et al (2005) and sub-grid turbulence was parameterized using 1.5-order turbulence-kinetic-energy closure. The simulations were initialized using the 12 UTC radiosonde profile at on 25 March 2009, with a cloud layer with an ice content of $1 \mathrm{~g} \mathrm{~kg}^{-1}$ added between 5 and $7 \mathrm{~km}$ to represent the cirrus anvil overhanging Fort Worth. Small-amplitude random temperature perturbations were added to the initial flow to seed turbulent motions. To evaluate the impact of the observed background winds on the simulated cloud structures, experiments were performed both with and without these winds.

In the zero-wind case, lobe-like structures develop at cloud base by around 30 minutes of model integration (Figure 6a). These lobes arise from the sublimation of falling snow within the unsaturated sub-cloud layer, which cools and humidifies this layer. This cooling destabilizes the sub-cloud layer, causing small convective thermals to develop that perturb the cloud base. Winds of around $30 \mathrm{~ms}^{-1}$ were observed by the radiosonde around cloud base, along with wind shear of order $0.001 \mathrm{~s}^{-1}$ (Figure $5 \mathrm{~b}$ ). With these winds included in the 
model initialization, the lobe development is modified. Snowfall again causes turbulent thermals to develop by 30 minutes of integration, but these lobes are elongated into wavelike structures by the ambient vertical wind shear. Figure $6 \mathrm{~b}$ shows the undersides of these features, with wind shear leading to the lobes overturning, apparent on the left edge of the image. Their wavelengths are approximately $2-3 \mathrm{~km}$ and amplitude $\sim 100 \mathrm{~m}$.

[Figure 6]

The conceptual modelling work of Anderson (2010) illustrates how the appearance of a preexisting cloud layer can be strongly modified by additional dynamical influences, such as wind shear, and a combination of processes is also anticipated to contribute to formation of asperitas. However, the restricted initialisation data for the model runs and the additional presence of the low level cloud limit the conclusions which can be drawn from interpreting the sightings at Fort Worth. Establishing a more accurate cloud height for asperitas occurrences has motivated the further investigations presented here.

Circumstances associated with further sightings of asperitas obtained in Europe during 2014 and 2016 are now investigated. Rather than seek local radiosonde and radar information, which is restricted to limited times and locations, vertical atmospheric profile information has been obtained from the European Centre for Medium range Weather Forecasting (ECMWF) high resolution operational model, for a location and time close to that of the digital images. The operational model data was chosen for this work over reanalysis datasets such as the ERA-interim dataset, because of the increased temporal and spatial resolution possible. The ERA-interim data only provides an analysis at $\sim 80 \mathrm{~km}$ resolution every 6 hours with intermediate forecast steps, whereas the high resolution model produces $\sim 25 \mathrm{~km}$ resolution data at hourly time steps. To offer further perspective on the synoptic conditions associated with each set of sightings, infra-red images from satellite passes close in space and time to each event are presented in Figure 7, and nearby ceilometer data for corroboration of the modelled cloud base height are given in Figure 12.

[Figure 7]

\section{(b) Belgium}

Figure 8a shows the temporal and spatial distributions of eleven sightings made over northern Belgium about 1600 UTC on the 9 June 2014. An image from the cluster of sightings made in Belgium is shown in Figure 2. Figure 7a shows a thermal infra-red satellite image a few hours before the first sighting, the outline box marks the position of the cluster of sightings. Around the positions of the asperitas sightings there are convective systems, distinguishable in bright white due to the very low temperatures associated with their high cloud tops. Convective systems such as this are known to emit gravity waves which can be 
experienced at distances of 100s of $\mathrm{km}$ (Lane et al 2012), which provide a possible source of the cloud oscillations observed.

Profiles obtained from ECMWF model data on the same day are shown in Figure 8b, for a grid point within the cluster of sightings at 16UTC, the location of which is marked by a cross hair in figure 8a. Several parameters have been extracted from the model, which are shown as vertical profiles in the five panels of Figure $8 \mathrm{~b}$ : temperature and potential temperature, relative humidity $(\mathrm{RH})$, wind speed components, Brunt-Väisälä frequency and horizontal wind shear. The Brunt-Väisälä frequency $(N)$ is the buoyancy frequency obtained by a vertically displaced parcel of air in a statically stable environment. Larger values of $N$ correspond to larger static stabilities.

[Figure 8]

The temperature and $\mathrm{RH}$ data suggests that the cloud base in this case was at about $750 \mathrm{~m}$ above the surface, although this is not particularly well defined. Ceilometer measurements from Uccle indicate a cloud base of about $1000 \mathrm{~m}$ during the period of the sightings (figure 12a). Both sources of information suggest the cloud layer was well below the freezing level, at about $3500 \mathrm{~m}$. The boundary layer which extends to the cloud base is unstable, which encourages vertical motion. $N$ increases to $0.02 \mathrm{~s}^{-1}$ through the depth of the cloud, implying that the cloud is statically stable. Here the dry Brunt- Väisälä frequency is used, but in a cloud the air is saturated and the effects of latent heating need to be considered. Durran and Klemp (1982) proposed an estimate of the saturated Brunt- Väisälä frequency $N_{\mathrm{m}}$, which accounted for these effects. $N_{\mathrm{m}}$ has accordingly been computed for vertical regions of the profiles that were within cloud. It was found that $N_{\mathrm{m}}$ was less than $N$, but $N_{\mathrm{m}}$ was still greater than the typical tropospheric value of $0.01 \mathrm{~s}^{-1}$ (e.g. Ambaum, 2013), and its variations highlighted the same stable regions as with $N$. Consequently $N$ is used for the remainder of this analysis. At cloud base, there is horizontal wind shear of $0.01 \mathrm{~s}^{-1}$. The wind shear and Brunt-Väisälä frequency can be combined to derive the Richardson number, a quantity used to estimate the occurrence of turbulence in statically stable air. Mcllveen (1998) defines the Richardson number Ri as

$$
R i=\frac{N^{2}}{S^{2}}
$$

where $N$ is Brunt- Väisälä frequency, and $S$ is the wind shear with dimensions of speed per unit change in height and units of $\left(\mathrm{ms}^{-1}\right) \mathrm{m}^{-1}$. When air is statically stable $\left(N^{2}>0\right)$ with low wind shear, the Richardson number exceeds its critical value of 0.25 and the flow will be laminar. If $R i<0.25$, wind shear can lead to the development of Kelvin-Helmholtz instability, and turbulent flow. Estimates of the Richardson number within the cloud base suggest that generation of Kelvin-Helmholtz waves is unlikely. 
[Figure 9]

(c) Dorset

Times and locations of the images obtained in Dorset on 9 July 2016 are plotted in Figure 9a, which were around 16UTC. In Figure 7b there is cloud present over the south western UK which, given its elongated appearance, is likely to be a weather front as seen in the synoptic chart for 12UTC for that day (Figure 10). Weather fronts can cause disturbances such as gravity waves in the atmosphere due to the vertical motion associated with a meeting of air masses. Figure $9 \mathrm{~b}$ shows the associated vertical profiles from the ECMWF model. Firstly, the cloud base is low at $500 \mathrm{~m}$ (which is corroborated by the ceilometer measurements from Middle Wallop, figure 12b) and the boundary layer below it is unstable. Secondly, the BruntVäisälä frequency $N$ increases through the base of the cloud to $0.03 \mathrm{~s}^{-1}$, which is indicative of very stable air. Finally, the wind shear also increases in this region although the peak wind shear is slightly offset vertically which could allow for Kelvin-Helmholtz instability at the base. Thirdly, the freezing level is at $3500 \mathrm{~m}$, well above the characteristic cloud base features.

[Figure 10]

[Figure 11]

\section{(d) Peterborough}

The time and location of sightings obtained in the Peterborough area between 14 and 15 UTC on the 27 August are shown in Figure 11a. The satellite image from that time shows a convective system to the north west of the area. Distant flashes of lightning were observed by one of the authors (GJM) from the north west of the region whilst the asperitas was overhead. The ECMWF data in Figure $11 \mathrm{~b}$ suggests a cloud base height (from the RH data) at $1200 \mathrm{~m}$, which is in good agreement with cloud base height obtained from ceilometer measurements (Figure 12c) situated at the Met Office research site at Cardington, a few $\mathrm{km}$ from the position of image $4 \mathrm{~b}$. The boundary layer is again unstable: at the cloud base the Brunt-Väisälä frequency increases to $0.016 \mathrm{~s}^{-1}$ and the horizontal wind shear at the cloud base is $0.015 \mathrm{~s}^{-1}$. The Richardson number at this height is $\sim 1$, indicating that Kelvin Helmholtz instability is unlikely.

[Figure 12] 


\section{Discussion}

In the previous section case studies of atmospheric conditions associated with asperitas sightings have been examined. For the Fort Worth case study, where the cloud base is of unknown height, local radiosonde profiles and modelling indicate that horizontal wind shear can be significant in affecting the appearance of the cloud base. This is therefore a factor to consider in the formation of asperitas-like cloud features. To clarify the cloud base position, three European examples were examined where the synoptic conditions and vertical profiles from the ECMWF model were available, together with local ceilometer observations for validation. In all three cases the asperitas cloud was found to form well below the freezing layer, thus removing the possibility of ice in its formation.

The ECMWF data showed three similar vertical structures of the atmosphere, with, in all three cases, an unstable boundary layer topped with cloud. Within the cloud base there were regions of enhanced stability inferred from $N=0.02 \mathrm{~s}^{-1}$. (A typical tropospheric value is usually $0.01 \mathrm{~s}^{-1}$ ). At roughly the same heights there are regions of horizontal wind shear (of $\sim 0.01 \mathrm{~s}^{-1}$ ), which have $R i>0.25$ meaning Kelvin Helmholtz instability is unlikely apart from the Dorset case which has a wind shear maximum at a lower altitude than the region of stability. Table 1 summarises the information obtained from the ECMWF model data around the locations of the sightings.

[Table 1]

Whilst the Richardson number considerations from the model data indicate that turbulence is unlikely in the cloud region, limitations in the modelling mean that its occurrence in the real natural situation cannot be ruled out. The model data used here is from a global model with a $200 \mathrm{~m}$ vertical resolution and $25 \mathrm{~km}$ horizontal resolution, which allows good estimates of the cloud base height, as the ceilometer data comparisons further corroborate. However, turbulence is not explicitly derived on a local scale within the model, and consequently an empirical turbulence diagnostic such as the Richardson number has to be used instead to parametrise it. Because of the finite resolution of the model very fine scale features which could lead to a small $R i$ are not resolved, turbulence and Kelvin-Helmholtz instabilities could still be observed even at larger values of $R i$ (Sharman et al 2006).

In all our case studies there appears to be wind shear and a stably-stratified cloud layer. It is hard to conclude from the model profile data (and Richardson number considerations) alone whether turbulence is the cause of the undulating cloud base. But Kelvin-Helmholtz waves can be highly localised and only persist for 20-30 minutes before dissipating due to turbulence and the stabilization of the wave-bearing layer.

In the European cases, sightings were made over large areas for periods of two hours or more, suggesting a persistent, widespread process. One phenomenon which can explain such persistence is the atmospheric gravity wave. As discussed in the introduction, gravity waves can be generated from many different atmospheric disturbances. For the Belgium, 
Peterborough and Fort Worth events there are identifiable gravity wave sources in the form of convective systems in the vicinity of each cluster of sightings. For the Dorset event the only visible large scale source of gravity wave activity appears to be from that of a passing front, which is apparent in the satellite image in Figure 7b. Gravity waves can be emitted from a weather front from the vertical motions within frontal cloud. Another alternative source of gravity waves may be from a dynamic source, such as a local spontaneous imbalance of the flow. Knox (2008) showed that a major factor in this imbalance process is relative vorticity advection. Relative vorticity advection was calculated using the same ECMWF data and is shown in Figure 13. It can be seen there are clusters of enhanced relative vorticity advection in the region which could provide a further source of atmospheric gravity waves beyond those generated by the front.

[Figure 13]

As gravity waves are common in the atmosphere, this invites the question of why asperitas is not a more common phenomenon? This draws attention to the complex combination of thermodynamic and dynamic phenomena in forming a particular cloud. Within a stratiform cloud, a stratified region may form which is able to act as a duct for the propagation of gravity waves. Gill (1983) showed that, if the frequency of the gravity wave is smaller than the Brunt-Väisälä frequency of the stratified layer but nevertheless exceeds the BruntVäisälä frequency of the layer above, gravity waves could be ducted. In our examples the angular frequency of the gravity waves $\omega$ would need to lie between $0.02 \mathrm{~s}^{-1}$ and $0.01 \mathrm{~s}^{-1}$. Given $\omega=k U$, where $k$ is the wavenumber (with dimensions of inverse length), and taking $U$ in our cases to be of order $10 \mathrm{~m} \mathrm{~s}^{-1}$, the associated wavelengths would be approximately 500-1000 m which is not inconsistent with the observations in Figures 1 to 4. Further, wind shear associated with each layer could act to distort the waves in the cloud base, to give asperitas its wavelike yet chaotic features.

On the basis of the case studies shown here, it is likely that the features of asperitas form within an existing stratiform cloud. The asperitas is therefore a supplementary feature which is formed by a gravity wave ducted or trapped within the stratified region that is already present within the cloud. Additionally, the wind shear within the cloud would act to deform the waves, which is consistent with the chaotic wave forms observed. However, given the inconclusive turbulence metrics from the ECMWF model it cannot be entirely ruled out that the wave like perturbations could have been formed from Kelvin-Helmholtz instabilities within the cloud. This represents a further category of cloud conditions associated with oscillatory motions, beyond those of lenticularis and mammatus clouds which are generated by mountains and small scale convective systems respectively. 


\section{Conclusions}

Asperitas has a dramatic appearance which, by the activities of citizen science, has largely made its own case for classification through the committed coordination of the Cloud Appreciation Society. Working from the WMO conventional definitions of cloud genera, species, varieties and supplementary features, asperitas is a supplementary feature. This is consistent with the classification of mamma in providing supplementary features, whereas varieties are used to describe macroscopic features of the cloud, as opposed to features that occupy only part of a larger cloud.

Casual usage of the earlier term asperatus acquired some acceptance, but the entry of popular terminology into widespread common usage before the cloud has received any scientific scrutiny presents an unprecedented situation in the history of cloud nomenclature. The widespread formal adoption of the term asperitas is therefore a significant step.

The citizen science endeavour of collecting images has demonstrated itself to be particularly well suited to identifying a rare but distinctive phenomenon. This is because it has permitted the early sightings to be validated by more and more images of similar phenomena, aided further by reliable geolocation and time data. Robust evidence for a consistent form has therefore emerged. This, in turn, has allowed some theories about formation to be disregarded. What remains, is support for a role of an atmospheric gravity wave or instability causing an oscillatory motion within an existing stratiform cloud. For this to be an effective process explaining the cloud form observed, the cloud has to be highly stratified with wind shear present, to cause the gravity waves to become trapped and deformed.

Through the international work of citizen scientists, these spectacular cloud formations have now obtained their place in the nomenclature of clouds.

\section{Acknowledgements}

The MSc work of Graeme Anderson benefited from suggestions made by Margaret LeMone at NCAR. Andrew Barrett assisted with the CM1 model. The images in Figures 1 to 4 were obtained by contributors to the Cloud Appreciation Society, and in particular Figure 1(a) by Ken Prior, Figure 1(b) by Krista English, Figure 2 by Peter Verschueren, Figure 3 by Roy Farmer and Figure 4a by Derek Wanstall. Figure 4b was provided by Graeme Marlton. Data for Figure 5(a to d) were obtained from the University of Wyoming website: Figure 5(c) was obtained from NOAA's NEXRAD operational S-band radar, and (d) from GOES satellite data. ECMWF archived operational products used in Figures 8, 9, 11 and 13 have been obtained from the ECMWF archive. The Dundee satellite receiving station provided the satellite images shown in figure 7. Ceilometer data in Figure 12 was provided by courtesy of the Met Office, and the Royal Meteorological Institute of Belgium. (The CL51 ceilometer deployed in Uccle at the Solar-Terrestrial Centre of Excellence is funded through the Belgian federal government). The Met Office synoptic chart in Figure 10 was provided by Roger Brugge. 


\section{References}

Anderson, G.D., 2010. Asperatus: the application of cloud classification to a suggested new cloud type MSc dissertation, University of Reading, UK

Ambaum, M.H.P, 2010. Thermal Physics of the atmosphere, Wiley Blackwell, Chichester UK

Barnard L., A. Portas, S.L. Gray and R.G. Harrison, 2016. The National Eclipse Weather Experiment: An assessment of citizen scientist weather observations Phil Trans Roy Soc A 374, 20150220 (doi:10.1098/rsta.2015.0220)

Bryan, G.H., 2002. An investigation of the convective region of numerically simulated squall lines. Ph.D. thesis, The Pennsylvania State University, pp6-64

Durran, D.R. and Klemp, J.B., 1982, On the effects of moisture on the Brunt-Väisälä frequency, J. Atmos. Sci., 39(10), pp2152--2158

Gill, Adrian E., 1982, Atmosphere-ocean dynamics, Academic Press

Knox, J.A., McCann, D.W. and Williams, P.D., 2008, Application of the Lighthill-Ford theory of spontaneous imbalance to clear-air turbulence forecasting, J. Atmos. Sci., 65(10), 32923304.

Lane, T.P., Sharman, R.D., Trier, S.B., Fovell, R.G. and Williams, J.K., 2012. Recent advances in the understanding of near-cloud turbulence, Bulletin of the American Meteorological Society, 93(4)

Morrison, H., J.A. Curry, and V.I. Khvorostyanov, 2005. A new double-moment microphysics parameterization for application in cloud and climate models. part 1: Description. J. Atmos. Sci., 62, $1665-1677$.

Mcllveen, R., 1998. Fundamentals of Weather and Climate. 1st ed., Stanley Thornes Ltd, Cheltenham, pp358 - 364.

Sharman, R., Tebaldi, C., Wiener, G. and Wolff, J., 2006. An integrated approach to mid-and upper-level turbulence forecasting, Weather and Forecasting, 21(3), 268-287

Schultz, D.M., Kanak, K.M, Straka, J.M., Trapp, R.J., Gordon, B.A., Zrnić, D.S., Bryan, G.H., Durant, A.J, Garett, T.J., Klein, P.M., Lilly, D.K., 2006. The Mysteries of Mammatus Clouds: Observations and Formation Mechanisms. J. Atmos Sci, 63, 2409-2435

WMO, 1975. International Cloud Atlas - Volume I: Manual on the observation of clouds and other meteors. Geneva. 

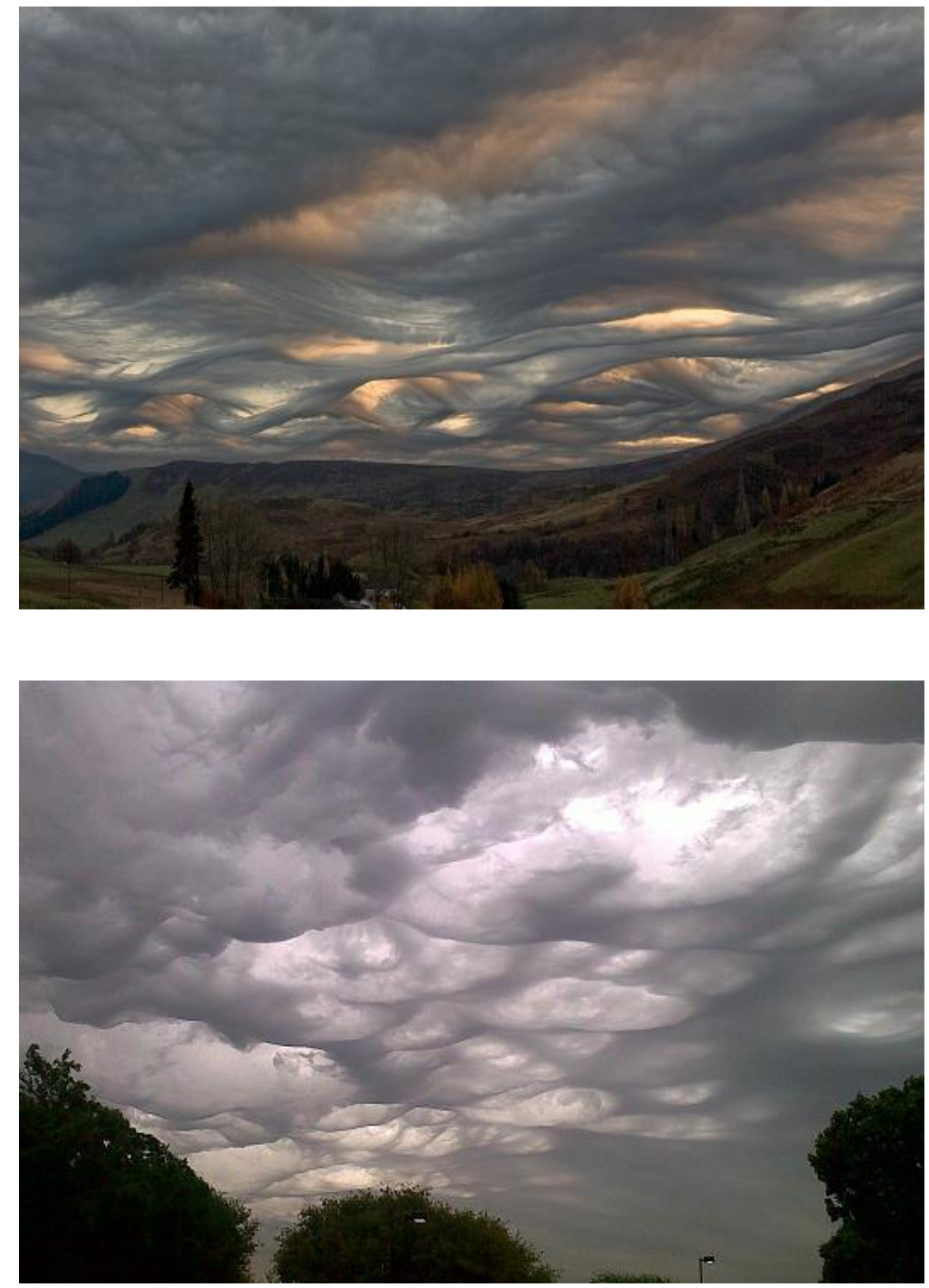

Figure 1 Examples of cloud over (a) Perthshire, Scotland, 1604UTC, 4 November 2008 and (b) Fort Worth, Texas, 1830UTC, 25 March 2009. 


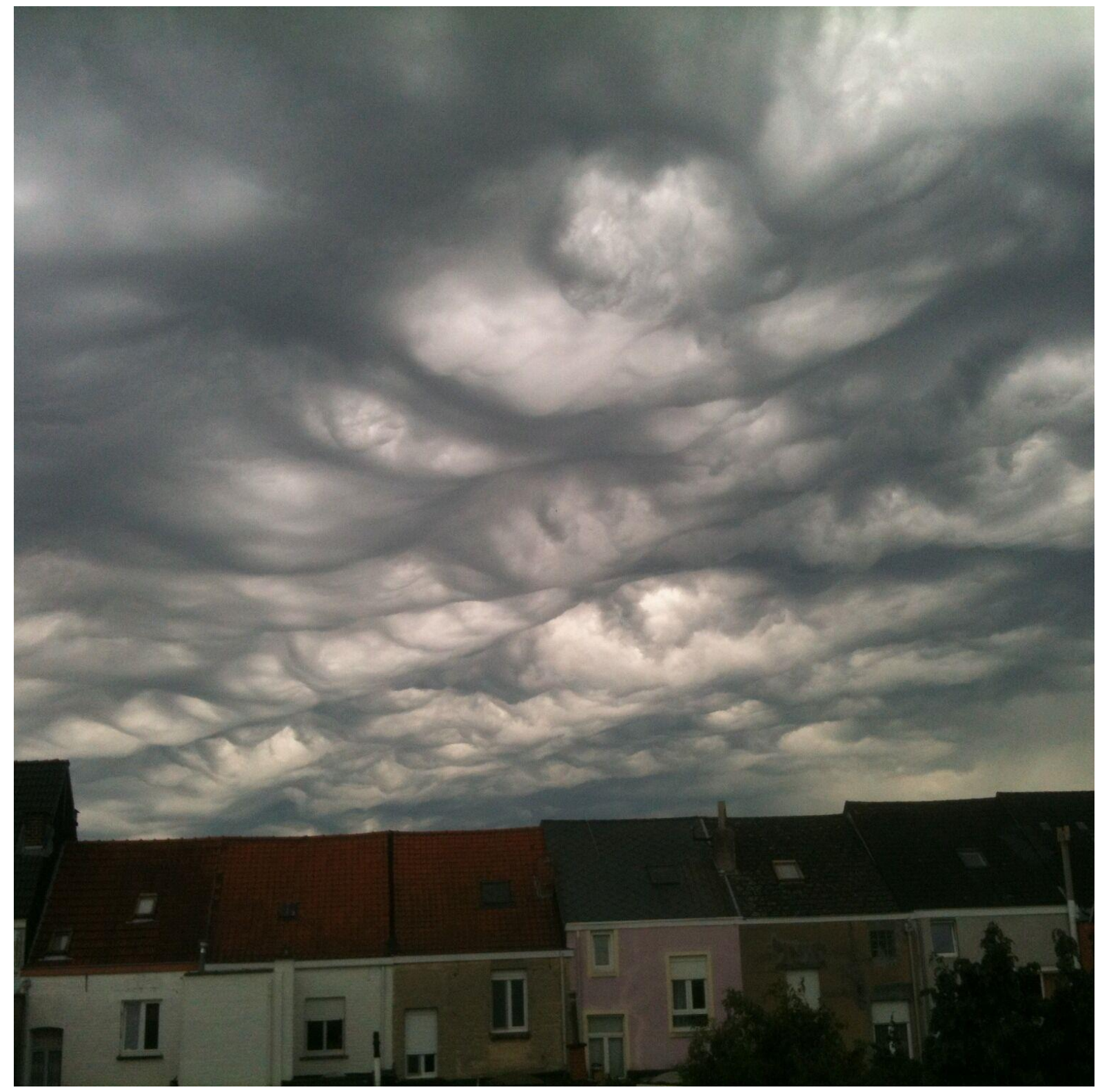

Figure 2 Image of cloud over Belgium at 1551UTC on 9 June 2014 (see Figure 8 for location). 


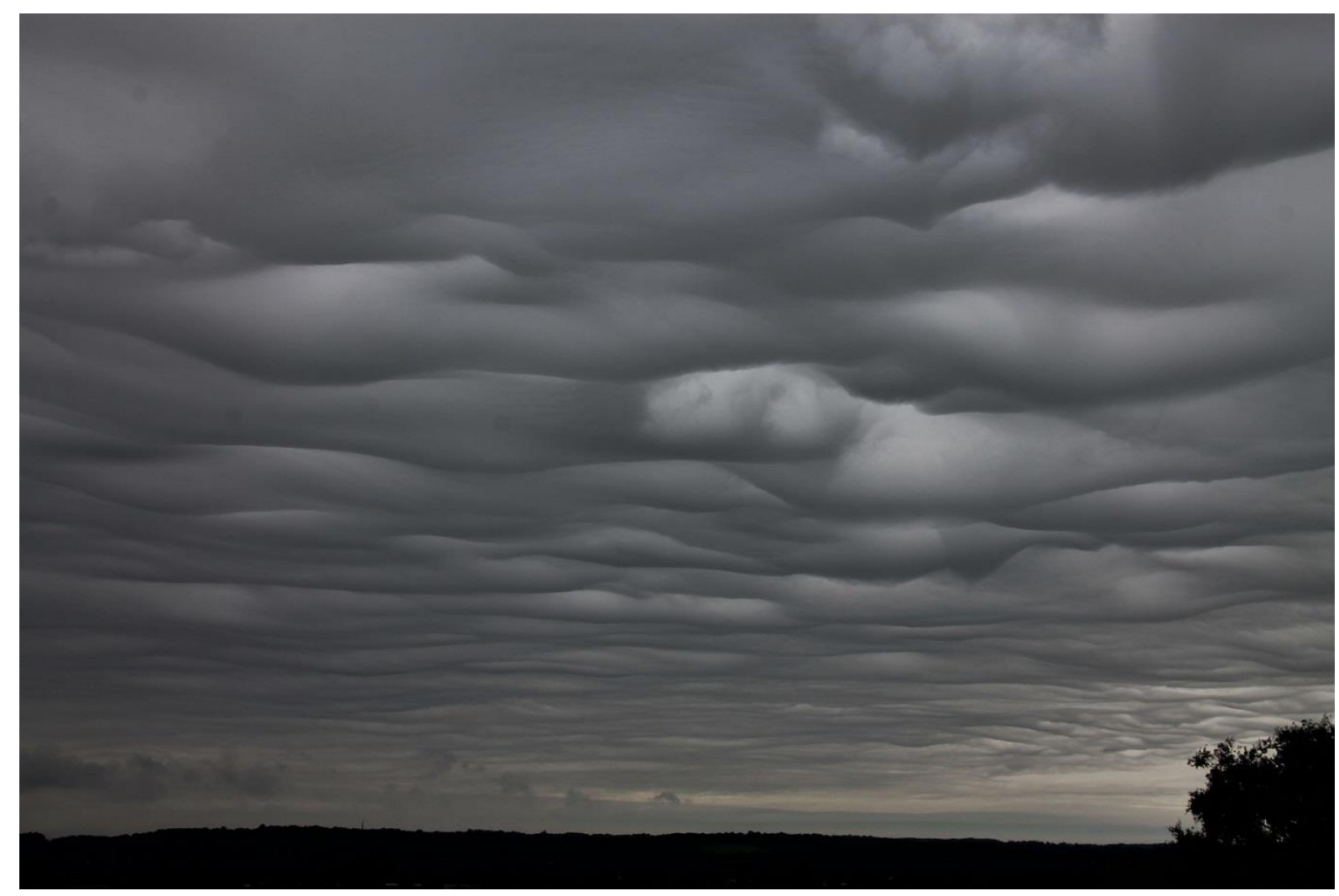

Figure 3 Image of cloud over Dorset at 1602UTC on 9 July 2016. (see Figure 9 for location). 
(a)

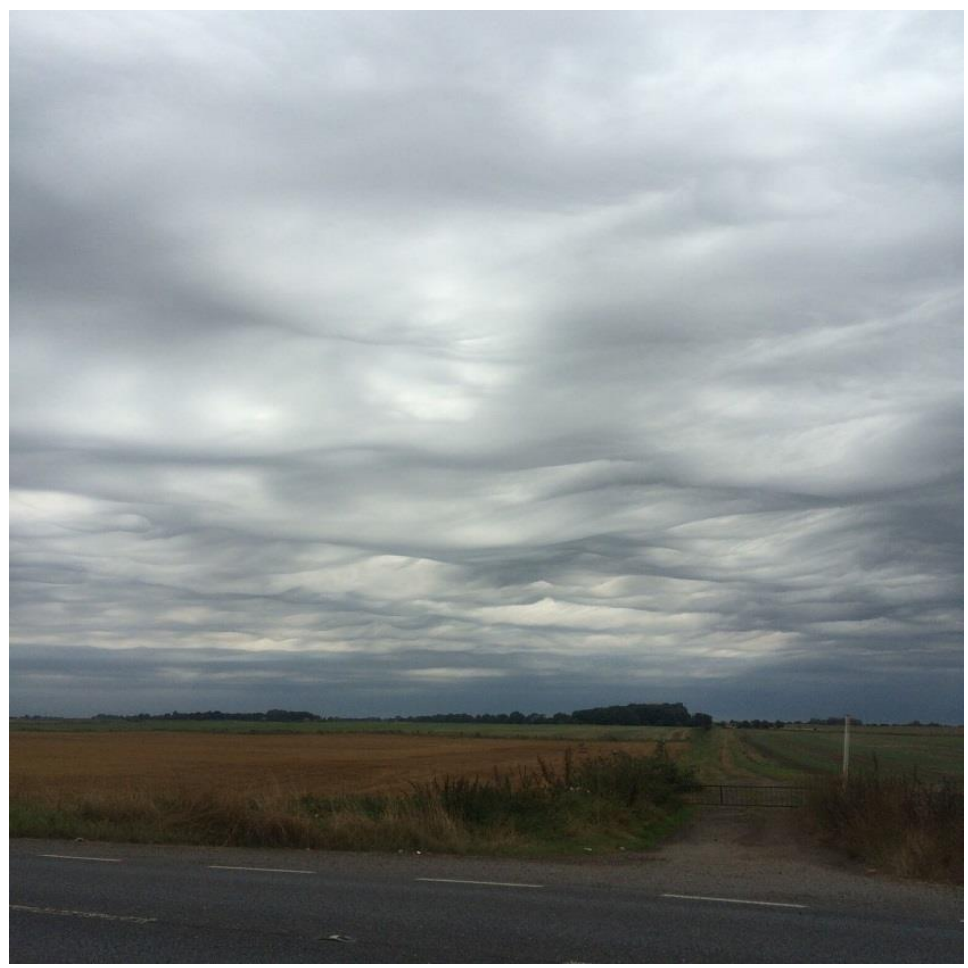

(b)

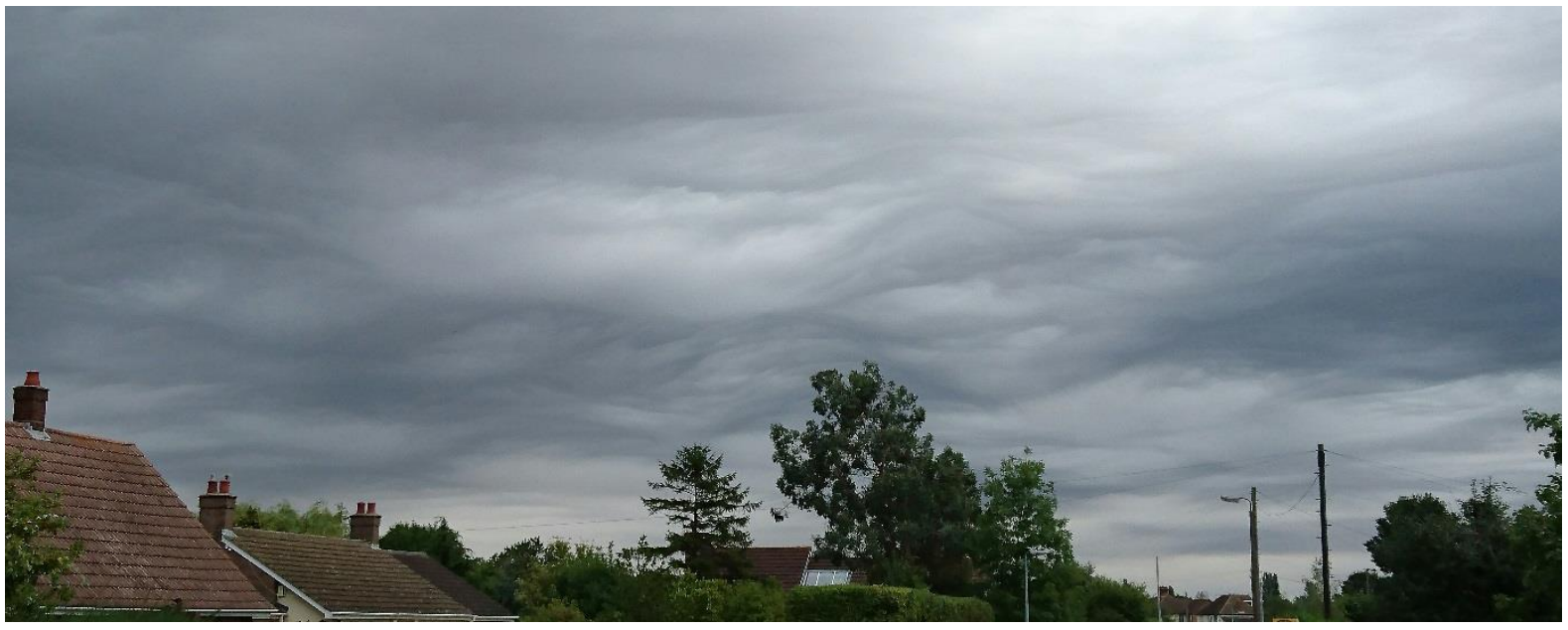

Figure 4. Image of cloud associated with the event around Peterborough on 27 August 2016, (a) at 1545UTC and (b) at 1313UTC. (See Figure 11 for locations). 

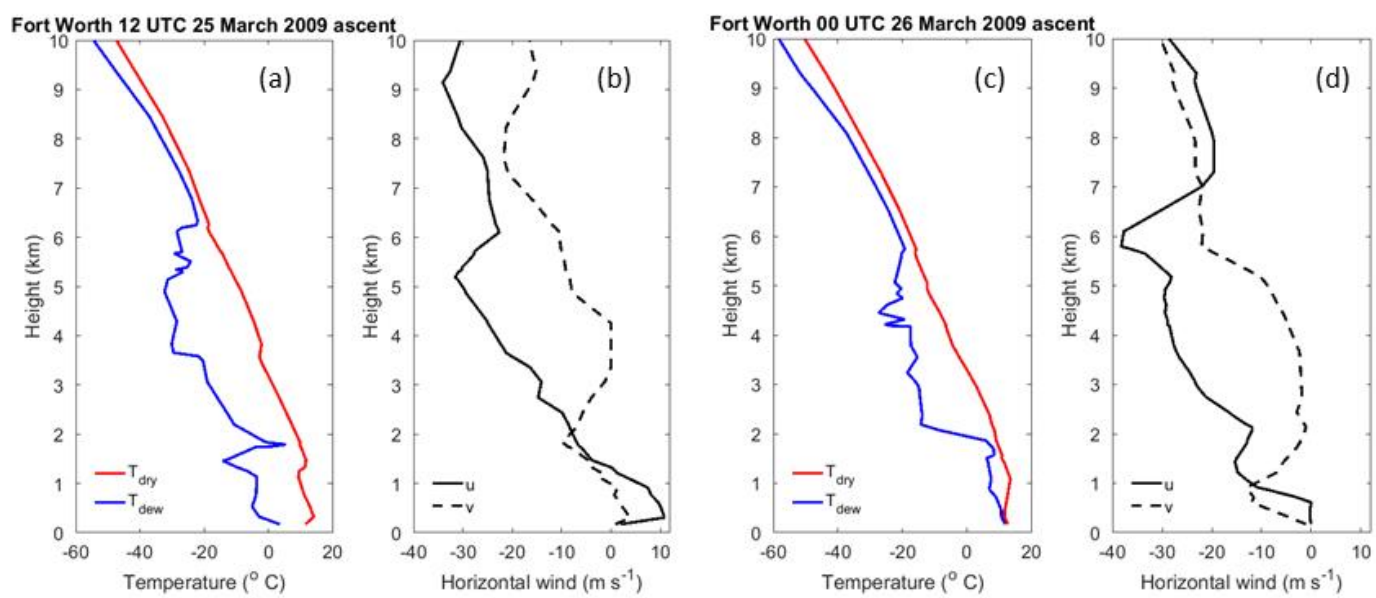

(e)
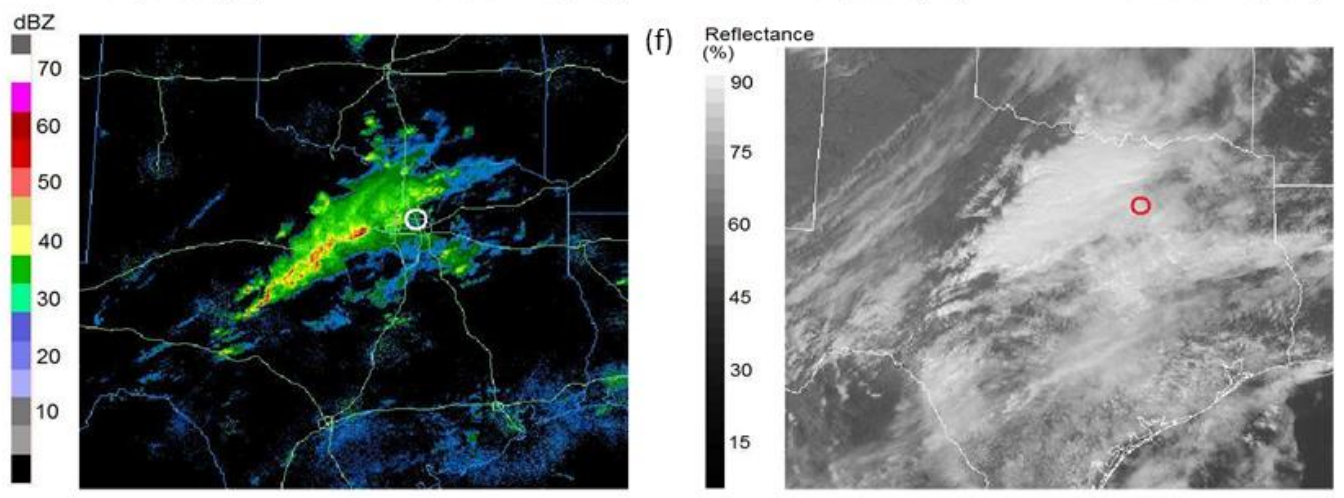

Figure 5 Data available associated with the formation observed at Fort Worth, Texas, 25 March 2009. (a) Thermodynamic and (b) wind soundings from 1200UTC, 25 March 2009. (c) Thermodynamic and (d) wind soundings 0000UTC, 26 March 2009. (e) Operational radar returns at 1826UTC, 25 March 2009. (f) GOES visible reflectance, 1815UTC, 25 March 2009. 

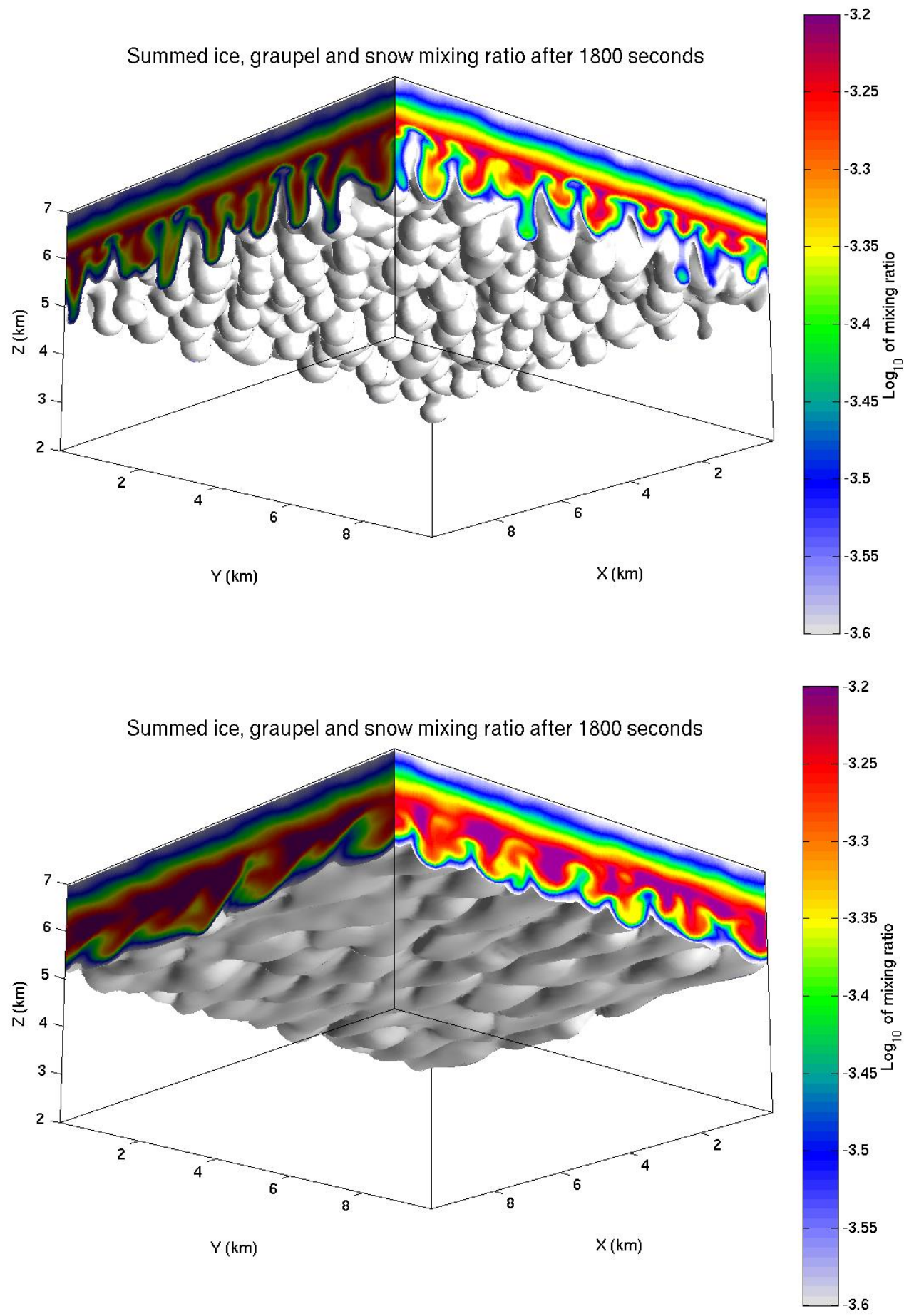

Figure 6. Total (ice, snow and graupel) mixing ratio after 30 minutes model simulation using the Fort Worth (12UTC, 25 March 2009) sounding (a) without horizontal winds in the initial condition and (b) using the observed horizontal winds from Figure 5 in the initial conditions. (An initial cloud layer mixing ratio of $1 \mathrm{~g} \mathrm{~kg}^{-1}$ was assumed and an ice mixing ratio of $1 \mathrm{~g} \mathrm{~kg}^{-1}$; a $2000 \mathrm{~m}$ cloud layer thickness was also assumed. Bottom surface threshold $=10^{-3.6} \mathrm{~kg} \mathrm{~kg}^{-1}$ ). From Anderson (2010). 



Figure 7. Infra-red satellite images from the Dundee receiving station for (a) 9 June 2014, (b) 9 July 2016, (c) 27 August 2016. In each case the region of the cloud sightings is highlighted with a red box. 
(a)

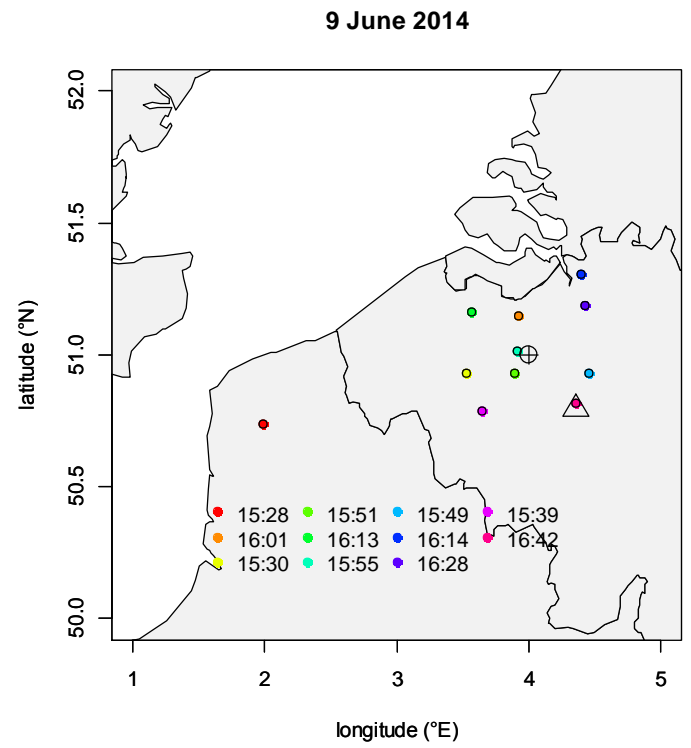

(b)
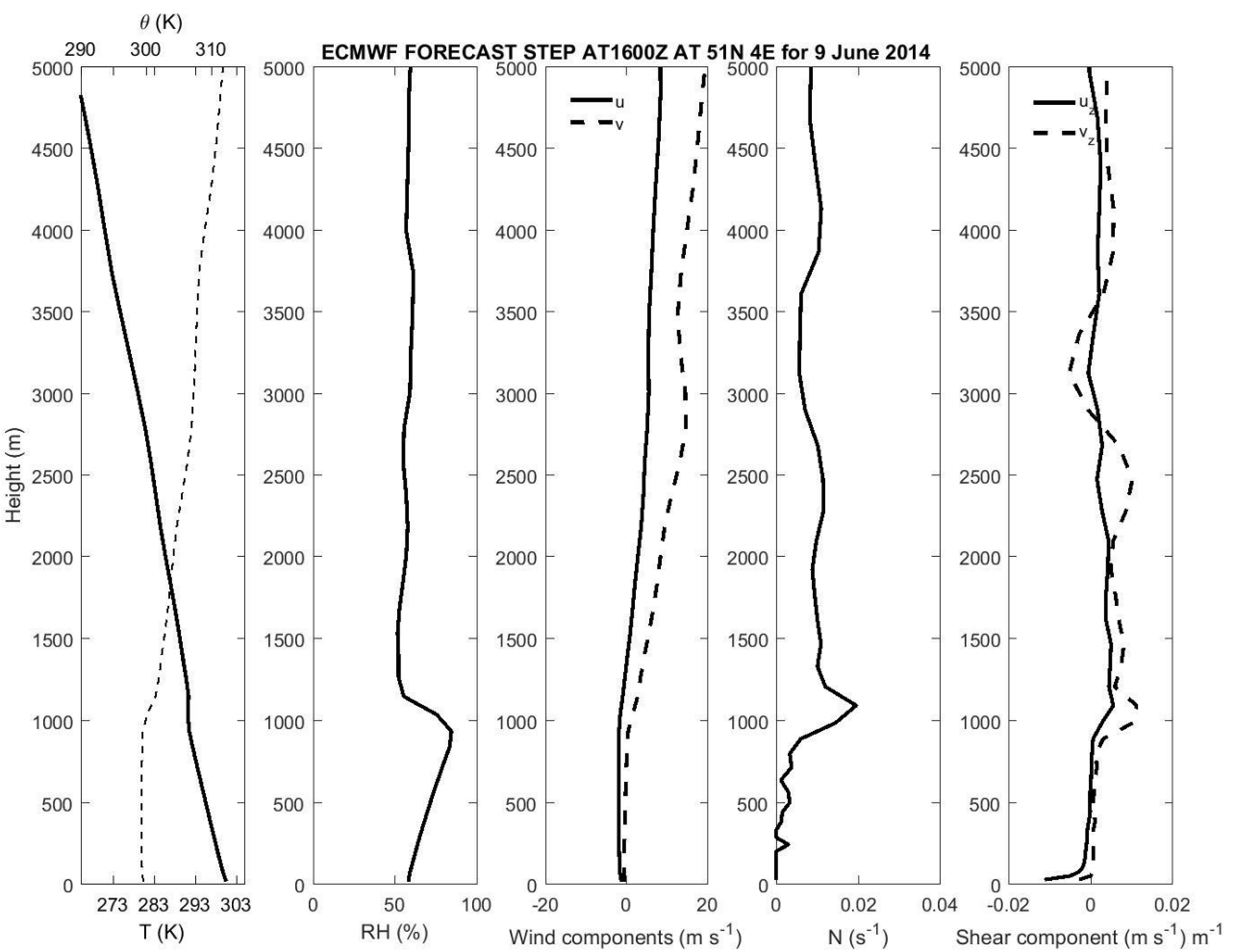

Figure 8. Data associated with the Belgium sightings on 9 June 2014. (a) Points show positions and times from which images were uploaded to the Cloud Appreciation Society. The triangle marks the position of the Uccle ceilometer. (Repeated sightings at the same location have been removed.) (b) Vertical profiles in the European Centre's forecast of temperature $T$ and potential temperature $\theta$, relative humidity $\mathrm{RH}$, wind speeds in the west-east $u$ and south-north $v$ directions, Brunt-Väisälä frequency and wind shear, for the position marked in (a) with a circled cross. 
(a)

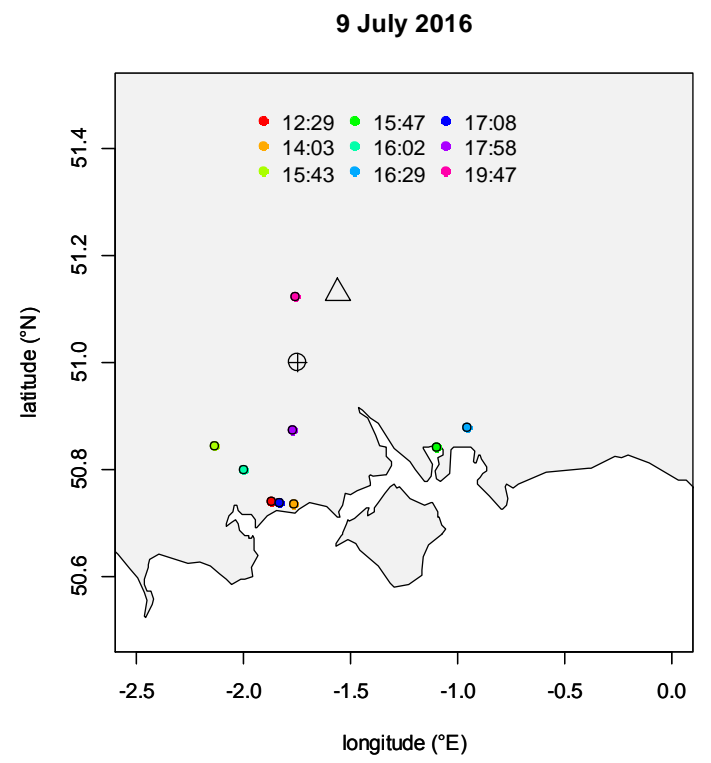

(b)

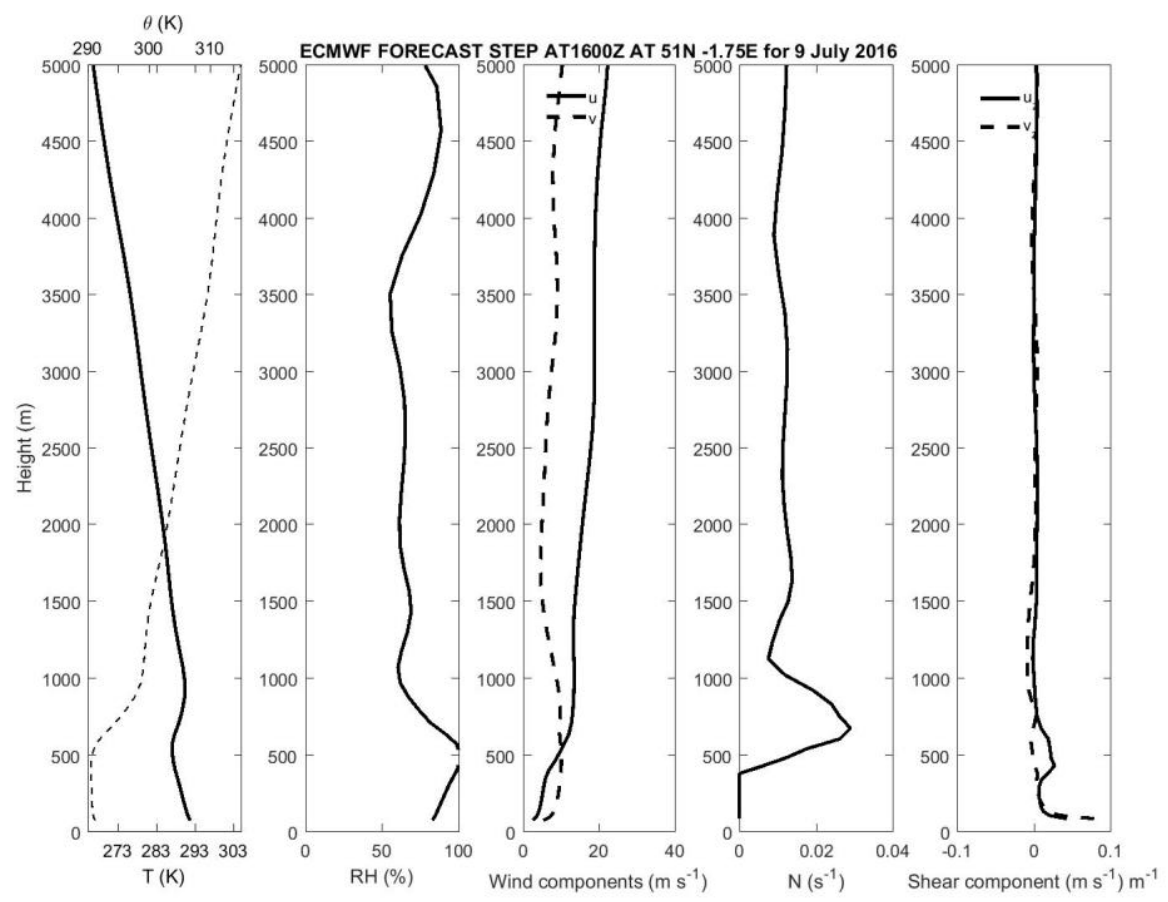

Figure 9. Data associated with sightings in Dorset on 9 July 2016. (a) Points show positions and times from which images were uploaded to the Cloud Appreciation Society, together with the position (triangle plot symbol) of the ceilometer at Middle Wallop. (The reports at 1708UTC, 1726UTC and 1808UTC were made at the same location.)) (b) Vertical profiles in the European Centre's forecast of temperature $T$ and potential temperature $\theta$, relative humidity $\mathrm{RH}$, wind speeds in the west-east $u$ and south-north $v$ directions, Brunt-Väisälä frequency $N$ and wind shear, for the position marked in (a) with a circled cross. 


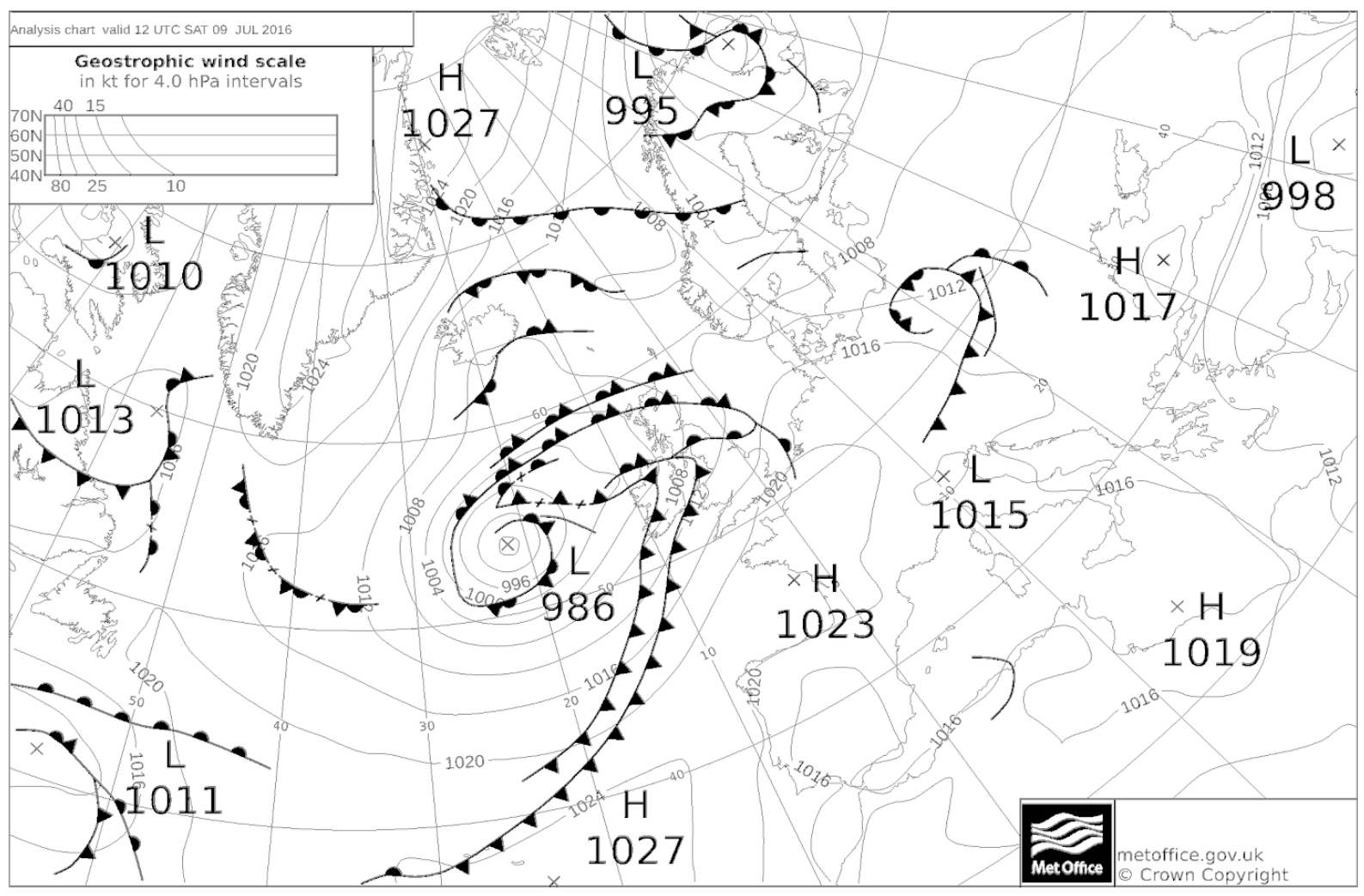

Figure 10 Met Office synoptic analysis for Europe and the Atlantic for 1200 UTC on the 9 July 2016, (C) Crown Copyright 
(a)

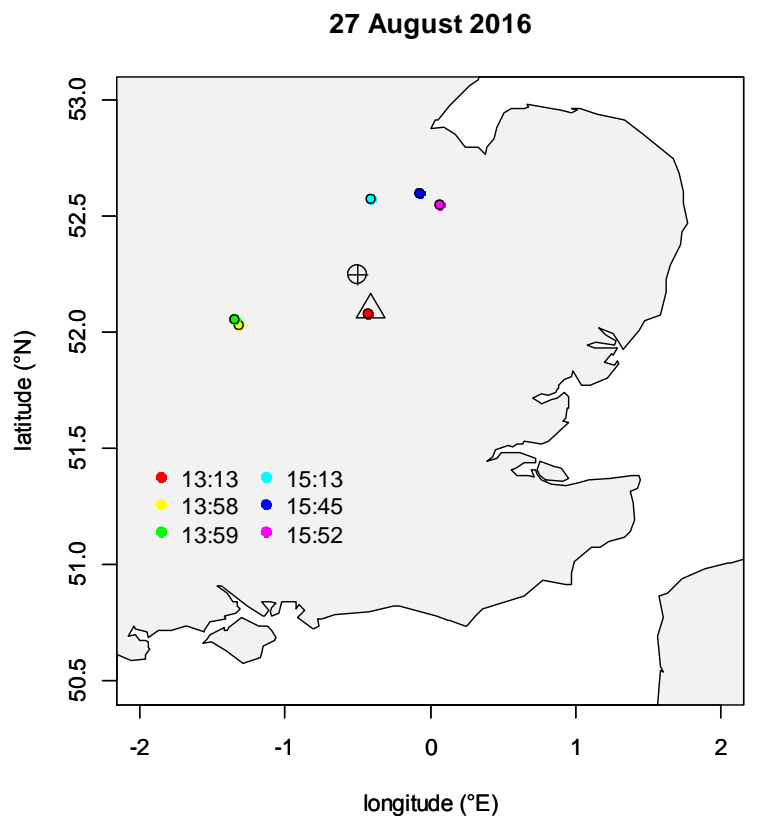

(b)



Figure 11. Data associated with sightings around Peterborough on 27 August 2016. (a) Points show positions and times from which images were uploaded to the Cloud Appreciation Society, together with the position (triangle plot symbol) of the ceilometer at Cardington. (b) Vertical profiles in the European Centre's forecast of temperature $T$ and potential temperature $\theta$, relative humidity $\mathrm{RH}$, wind speeds in the west-east $u$ and south-north $v$ directions, Brunt-Väisälä frequency $N$ and wind shear, for the position marked in (a) with a circled cross. 

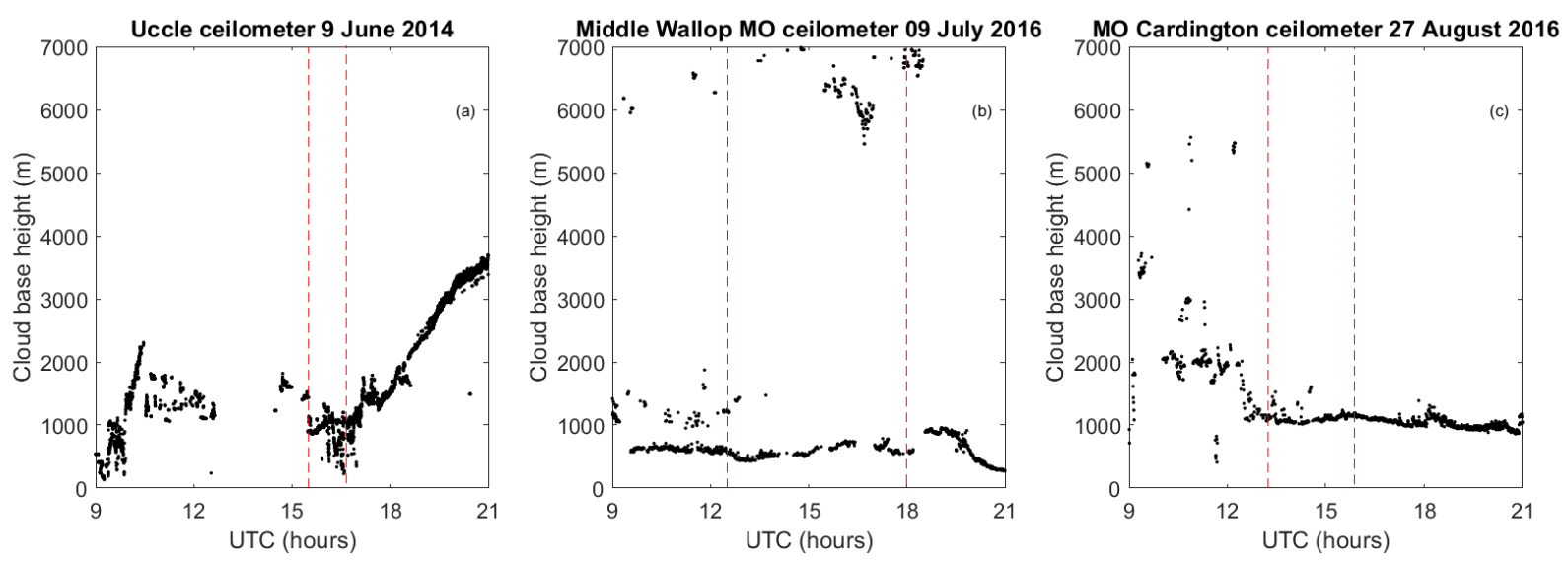

Figure 12 Time series of cloud base height determined by laser ceilometers over (a) Uccle on 9 June 2014, (b) Middle Wallop airfield on 9 July 2016 and (c) Cardington Meteorological Research Unit on 27 August 2016. The vertical red lines mark the intervals during which the case studies were made. 


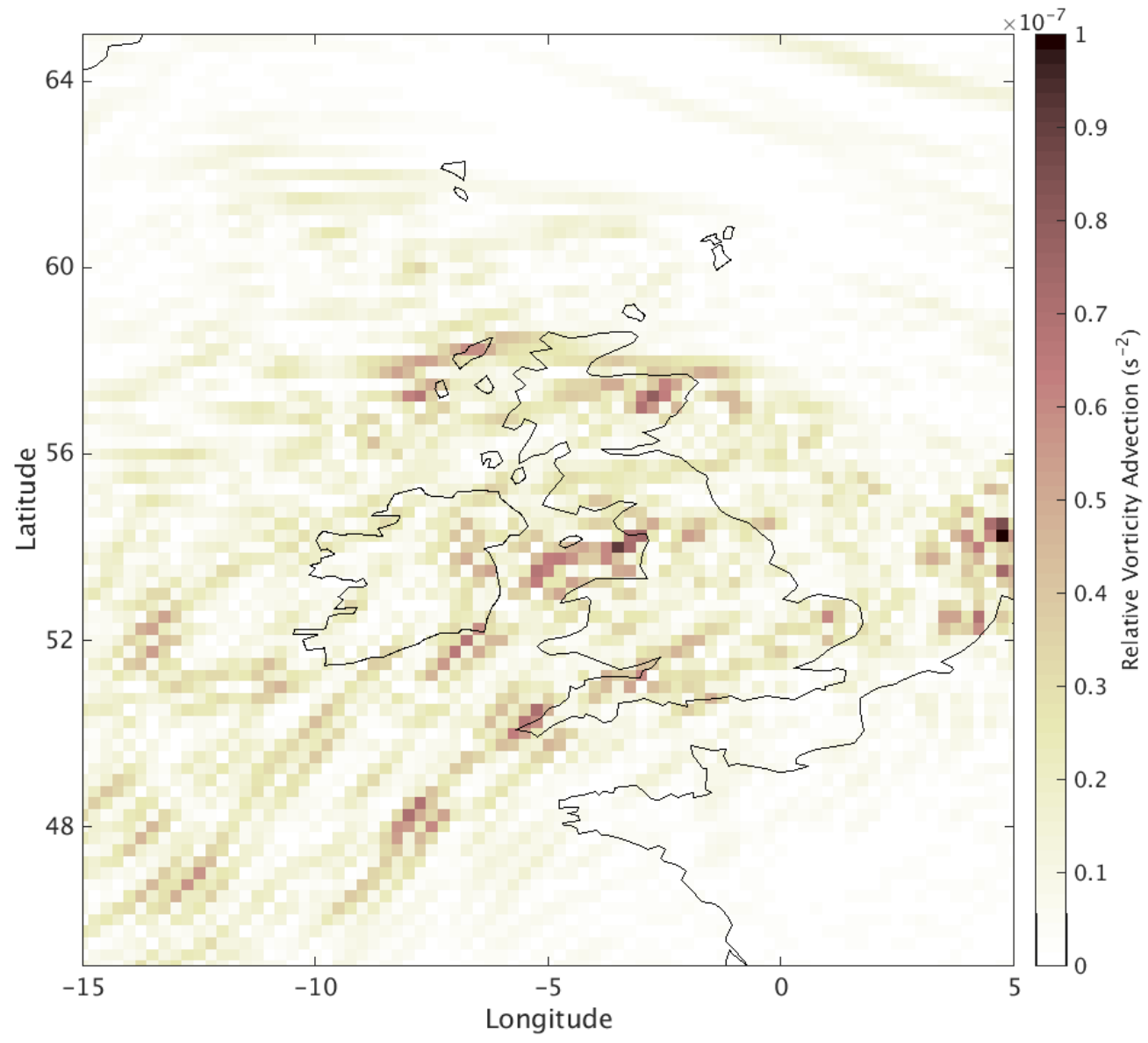

Figure 13 Rate of change of vorticity (i.e. the relative rate of vorticity advection, with units $\mathrm{s}^{-2}$ ) calculated at $500 \mathrm{hPa}$ from the ECMWF Hi-res model data for 1600UTC on 9 July 2016. 
Table 1. Summary of model data associated with asperitas sightings

\begin{tabular}{|l|l|l|l|l|l|l|l|}
\hline Location & date & $\begin{array}{l}\text { Boundary } \\
\text { Layer }\end{array}$ & $\begin{array}{l}\text { Cloud } \\
\text { base } \\
\text { height } \\
(\mathrm{m})\end{array}$ & $\begin{array}{l}\text { Freezing } \\
\text { level } \\
(\mathrm{m})\end{array}$ & $\begin{array}{l}\text { Cloud } \\
\text { top } \\
\text { shear } \\
\left(\mathrm{s}^{-1}\right)\end{array}$ & $\begin{array}{l}\text { Brunt- } \\
\text { Vaisala } \\
\text { frequency } \\
\mathrm{N}\left(\mathrm{s}^{-1}\right)\end{array}$ & $\begin{array}{l}\text { Richardson } \\
\text { number Ri }\end{array}$ \\
\hline Belgium & $\begin{array}{l}\text { 9 June } \\
2014\end{array}$ & unstable & 750 & 3500 & 0.01 & 0.02 & 4 \\
\hline Dorset & $\begin{array}{l}9 \text { July } \\
2016\end{array}$ & unstable & 500 & 3500 & 0.01 & 0.03 & 9 \\
\hline Peterborough & $\begin{array}{l}27 \\
\text { August } \\
2016\end{array}$ & unstable & 1200 & 4000 & 0.02 & 0.02 & 1 \\
\hline
\end{tabular}

